\title{
O mal-estar em tempos de pandemia: Considerações a partir da Psicanálise Lacaniana
}

\section{The malaise in times of pandemic: Considerations from Lacanian Psychoanalysis}

Jucélia Gonçalves de Souza Alves ${ }^{1 *}$, Rodrigo da Silva Almeida 2ª ; João Paulo Corumba de Santana $2^{1}$

\section{RESUMO}

O presente artigo traz uma leitura lacaniana do mal-estar na cultura em tempos de pandemia da COVID19. Trata-se de uma Pesquisa Psicanalítica do tipo teórica, através de um ensaio acadêmico. Esta discussão se justifica porque a atual pandemia, ao chegar ao Brasil, trouxe consigo um número alarmante de doentes e mortos, acrescida do despreparo e irresponsabilidade de algumas autoridades políticas no país e a necessidade do isolamento social como principal medida de mitigação do contágio do novo coronavírus. Diante do mal-estar na civilização decorrente da pandemia, problematizamos como o praticante de Psicanálise, ancorado em uma dimensão sócio-política do sofrimento psíquico, através de sua escuta, pode atuar como um agente de transformação social, subvertendo a lógica social vigente, produto da aliança entre os discursos universitário e capitalista, e apostando no sujeito da linguagem, ressaltando a sua singularidade e responsabilidade perante o seu desejo.

Palavras-chave: Pandemia. Mal-estar na cultura. Sofrimento Psíquico. Teoria Psicanalítica. Lacan.

\begin{abstract}
This article presents a Lacanian reading of the malaise in culture in times of the COVID-19 pandemic. It is a Psychoanalytic Research of the theoretical type, through an academic essay. This discussion is justified because the current pandemic, when it arrived in Brazil, brought with it an alarming number of sick and dead, added to the unpreparedness and irresponsibility of some political authorities in the country and the need for social isolation as the main measure to mitigate the contagion of the new virus. coronavirus. Faced with the malaise in civilization resulting from the pandemic, we problematize how the practitioner of Psychoanalysis, anchored in a socio-political dimension of psychic suffering, through listening, can act as an agent of social transformation, subverting the current social logic, product of the alliance between university and capitalist discourses, and betting on the subject of language, emphasizing its singularity and responsibility towards its desire.
\end{abstract}

Keywords: Pandemic. Discontent in the culture. Psychic Suffering. Psychoanalytic Theory. Lacan.

1 UNCISAL - Universidade Estadual de Ciências da Saúde de Alagoas. *E-mail: juceliagoncalvespsi@gmail.com

$2^{1}$ UFS - Universidade Federal de Sergipe 


\section{INTRODUÇÃO}

O presente artigo apresenta uma leitura lacaniana sobre o mal-estar contemporâneo em tempos de pandemia da COVID-19. Trata-se de uma Pesquisa Psicanalítica do tipo teórica, através de um ensaio acadêmico. Esta discussão se justifica porque a atual pandemia, ao chegar ao Brasil, trouxe consigo um número alarmante de doentes e mortos, acrescida do despreparo e irresponsabilidade de algumas autoridades políticas no país e a necessidade do isolamento social como principal medida de mitigação do contágio do novo coronavírus. Consequentemente, houve uma intensificação do malestar contemporâneo, mudando, assim, a rotina e os planos de vida das pessoas e impactando na saúde mental da população (COSTA; SIQUEIRA, 2020). Diante desse contexto, iremos problematizar neste ensaio a seguinte questão: o que pode a Psicanálise diante do atual mal-estar da pandemia?

\section{A PESQUISA PSICANALÍTICA DO TIPO TEÓRICA}

Utilizamos neste texto a metodologia da Pesquisa Psicanalítica do tipo teórica, que segundo Bastos (2009): “[...] é aquela que pode ser realizada a partir de textos dos pensadores da Psicanálise" (p. 17). Nesse sentido, trata-se de um retorno aos textos, todavia não se trata de uma mera reprodução das ideias dos autores, trazendo valiosas contribuições ao corpus psicanalítico, onde: “[...] Tal contribuição se dá, fundamentalmente, a título de ilustração, quando queremos saber realmente o que um dos ditos mestres da área da Psicanálise disse [...]” (BASTOS, 2009, p. 18).

Além disso, a Pesquisa em Psicanálise é sempre um empreendimento singular, cujo foco recai sobre o sujeito do inconsciente (FORTES; MACEDO, 2018; HARARI, 2018), tal como argumenta Lacan (1953-1954/2009): “[...] a análise como ciência é sempre uma ciência do singular [...]" (LACAN, 1953-1954/2009, p. 33). Para a escrita deste ensaio escolhemos alguns textos de Freud e Lacan e também fizemos uma revisão sistemática nas bases de dados da Coordenação de Aperfeiçoamento de Pessoal de Nível Superior (CAPES/MINISTÉRIO DA EDUCAÇÃO) e Google Acadêmico, utilizando as seguintes combinações de descritores: "Psicanálise AND pandemia da COVID-10", "Psicanálise AND Mal-estar na pandemia", selecionamos oito artigos que discutissem o 
mal-estar causado pela pandemia da COVID-19, sob o viés psicanalítico (KAMLER; THOMSON, 2015; RIBEIRO; MARTINS; LIMA, 2015).

Por fim, destacamos ainda que a seleção dos textos teve como base os procedimentos metodológicos propostos por Bastos (2009): 1) leitura exploratória dos títulos e resumos das publicações, seguida de uma 2) leitura seletiva, em que selecionamos aquelas que foram mais pertinentes ao estudo; 3) leitura analítica, realizamos uma leitura mais cuidadosa para a seleção definitiva dos textos que foram utilizados e, por último, uma 4) leitura interpretativa, em que os textos selecionados definitivamente foram lidos tendo como base a perspectiva psicanalítica lacaniana, buscando responder ao objetivo deste ensaio.

\section{A PSICANÁLISE DE ORIENTAÇÃO LACANIANA}

De acordo com Bastos (2009) a Psicanálise de Orientação Lacaniana trata-se de uma escola de Psicanálise que parte da releitura que o psicanalista Jacques Lacan (19011981) fez da obra de Freud. Seu intuito foi inicialmente fazer um retorno aos principais conceitos freudianos e retirar da Psicanálise leituras equivocadas oriundas principalmente do culturalismo e da fenomenologia.

Todavia, o retorno a Freud feito por Lacan não teve o intuito de estabelecer uma ortodoxia religiosa, que fizesse meramente uma repetição da obra freudiana (BASTOS, 2009). Lacan então reinterpretou a maioria dos conceitos de Freud e seus grandes casos clínicos, porém acrescentando a teoria Psicanalítica sua própria conceitualidade, tomando como base especialmente os pressupostos da linguística de Ferdinand Saussure, da antropologia de Claude Lévi-Strauss e da filosofia de Georg Wilhelm Hegel (ROUDINESCO; PLON, 1998).

Outra característica da Psicanálise de Orientação Lacaniana é o seu caráter singular e o seu foco no sujeito do inconsciente. Nesse sentido, Lacan (1953-1954/2009) destaca que ao elaborar a sua teoria, Freud teve como foco a verdade do sujeito, pois: "[...] No dizer do próprio Freud, esse interesse deu às suas relações com os seus doentes um caráter absolutamente singular" (LACAN, 1953-1954/2009, p. 33). Prossegue afirmando que: 
esses casos singulares se prestem não obstante a alguma generalidade, desde que há mais de um analista. Mas a experiência analítica com Freud representa a singularidade levada ao seu extremo, pelo fato de que começava a construir e a verificar a própria análise. [...] A análise é sempre uma experiência do particular. A experiência verdadeiramente original desse particular assume, pois, um valor ainda singular [...] (LACAN, 1953-1954/2009, p. 33-34).

Harari (2018) acrescenta que os efeitos terapêuticos podem, sim, ser alcançados em uma análise. Todavia, a terapêutica não se constitui como o objetivo do tratamento, mas sim como um acréscimo. A autora também sustenta ser uma ilusão pressupor que a Psicanálise visa o restabelecimento do bem-estar do sujeito, tal como acontece com as psicoterapias em geral. Consequentemente, não se trata de uma "psicoterapia psicanalítica”, mas sim de uma Psicanálise que intervém diante do mal-estar na cultura e do sofrimento psíquico dos sujeitos.

A autora acrescenta que a ética do psicanalista vai na contramão das tentativas de terapeutizar o psiquismo e alerta para as tentativas de "psicoterapeutização" que a Psicanálise tem sofrido na atualidade, sendo incompatível conciliar os ideais terapêuticos da medicina com a prática lacaniana, tendo em vista que só é possível pensar a ética da Psicanálise, que é uma ética do bem-dizer: “[...] quando o desejo do analista se torna mais forte que o de ser mestre. Para Lacan, às vezes é tão cara a condição de doente, que este procura apenas a autenticação: ser tratado de forma a lhe permitir continuar a ser doente [...]" (HARARI, 2018, p. 36), sendo por isso que Lacan (1966/2001, p. 10) faz a provocação: "[...] o doente demanda a cura?".

Diante disso, propomos aqui uma leitura do mal-estar da pandemia do novo coronavírus a partir da proposição lacaniana de sintoma, partindo de uma dimensão sociopolítica do sofrimento psíquico, que vai na contramão do psicologismo e da psiquiatrização estigmatizantes, evocando seu caráter político (ROSA, 2018), tendo em vista que, para Lacan (1974\2005): “[...] a Psicanálise é um sintoma. [...] Ela faz nitidamente parte deste mal-estar da civilização de que Freud falou. O mais provável é que as pessoas não se limitem a perceber que o sintoma é o que há de mais real" (LACAN, 1974\2005, p. 66).

Consequentemente, a Psicanálise de Orientação Lacaniana se caracteriza por ser uma práxis subversiva que, desde os primórdios do ensino de Freud e Lacan promove uma crítica sistemática à psicologização e medicalização do sofrimento psíquico, 
especialmente no que se refere à aplicação de um materialismo reducionista à clínica dos fatos mentais (SAFATLE, 2018).

Nesse sentido, Quinet (2020) sustenta que: “A Psicanálise é um sintoma do malestar na civilização desde que ela existe. Enquanto houver mal-estar na civilização, deve existir a Psicanálise como uma forma de tratamento do mal-estar do sujeito e da civilização" (QUINET, 2020, p. 15). A seguir, apresentaremos uma abordagem lacaniana sobre o mal-estar em tempos de pandemia.

\section{O MAL-ESTAR NA CULTURA EM TEMPOS DE PANDEMIA: CONSIDERAÇÕES A PARTIR DA PSICANÁLISE LACANIANA}

Nossa discussão sobre o mal-estar na contemporaneidade em tempos de pandemia teve como base a proposição de Freud (1930/2010) de que o processo de entrada do sujeito no laço social ocasiona o que ele chamou de mal-estar na civilização. Isso acontece porque existem várias exigências para que se possa conviver numa sociedade, requerendo dos sujeitos que eles abdiquem da satisfação de seus impulsos, renúncia que é muito difícil, pois desde o seu nascimento busca incessantemente a satisfação de seus desejos.

Ao discutir as exigências da vida social e a busca da felicidade, Freud (1930/2010) destaca que as restrições impostas pela cultura colocam obstáculos para a plena realização individual dos sujeitos e argumenta sobre a impossibilidade de uma felicidade plena, mas ao mesmo tempo convoca os sujeitos a não ficarem impotentes, devendo ir em busca daquilo que poderia lhes fazer feliz buscando, na medida do possível, se adaptar a essa realidade marcada pelo mal-estar, sustentando que:

[...] No sentido moderado em que é admitida como possível, a felicidade constitui um problema da economia libidinal do sujeito. Não há, aqui, um conselho válido para todos; cada um tem que descobrir à sua maneira particular de ser feliz (FREUD, 1930/2010, p. 58).

Além disso, nos ancoramos na Psicanálise de Orientação Lacaniana, especialmente na proposição de Lacan (1998) sobre a necessidade de que o psicanalista deve estar à altura do seu tempo, dizendo: "Que antes renuncie a isso, portanto, quem não conseguir alcançar em seu horizonte a subjetividade de sua época [...]” (p. 322). A convocação de Lacan nos auxiliará a refletir sobre o mal-estar na contemporaneidade em tempos de pandemia da COVID-19 e o que pode o praticante de Psicanálise diante disso. 
Consequentemente, os impasses do mal-estar contemporâneo, potencializados pela atual pandemia, têm desafiado a prática lacaniana na atualidade, especialmente no que se refere aos novos sintomas e à promoção da saúde mental dos sujeitos e instituições (HARARI, 2018). Nesse sentido, retomaremos os fundamentos da Psicanálise de Orientação Lacaniana, pois, tal como Lacan (1962-1963/2005) afirma que: “[...] o analista, não podemos esquecer, é, se assim me posso expressar, um interpretador" (LACAN, 1962-1963/2005, p. 25).

Diante disso, a proposição que fazemos aqui de uma abordagem lacaniana em tempos de pandemia tem como fundamento os pressupostos teóricos de Freud (1930/2010), em seu texto: “O mal-estar da civilização", pois entende-se que o momento epidemiológico que o mundo está enfrentando contribuiu para a intensificação do sofrimento e adoecimento psíquico dos sujeitos, marcado principalmente por várias reflexões/preocupações acerca da existência, sobretudo a finitude, impactando em diversas áreas da vida, especialmente na saúde e economia.

Partimos do pressuposto de que a atual pandemia do novo coronavírus afetou de forma significativa o modo de viver das pessoas, trazendo várias consequências para a sua saúde mental, tendo em vista a imposição de novos modos de viver, tais como: a quarentena, o isolamento e o distanciamento social, uso de máscaras, dentre outros aspectos, impulsionando os sujeitos a buscarem novas formas de ser e estar no mundo. Consequentemente, a pandemia impôs a todos nós uma nova realidade, marcada por diversas restrições e com isso foi necessária a reinvenção dos modos de viver, inclusive no que se refere à prática clínica (ROCHA, 2020).

Preuss et al. (2020) discorrem sobre os efeitos da pandemia na contemporaneidade argumentam que o advento da pandemia impactou em diversos âmbitos da vida, afetando dentre outras coisas, a saúde mental dos sujeitos, e que estas consequências psíquicas se manifestaram em dois sentidos: tanto fazendo emergir o sofrimento e adoecimento psíquico, quanto intensificando quadros já existentes.

Nesse sentido, assumimos o argumento de Droguett (2020) a respeito da importância de outras vias para o tratamento psicanalítico, enfatizando especialmente a utilização das mídias digitais enquanto recurso capaz de possibilitar suporte à subjetividade, evitando o perigo da contaminação, ao mesmo tempo em que fortalece o estabelecimento do laço social com o sujeito. 
Harari (2018) coloca que a prática lacaniana on-line não é uma exclusividade da pandemia, tendo em vista antes deste período já serem realizadas consultas virtuais, porém adquiriu características diferentes na atual crise sanitária. De acordo com Rocha (2020) na atual pandemia, uma das primeiras mudanças pelas quais nos deparamos foi a mudança no setting, que passou a ser dentro de casa, tendo em vista as restrições de atendimentos presenciais, facilitados por ferramentas virtuais que propiciaram a continuidade das análises.

Rocha (2020) prossegue destacando a que a prática lacaniana em tempos de pandemia tem confrontado tanto praticantes de Psicanálise quanto analisantes a enxergarem a si mesmos nas telas durante os atendimentos virtuais, chamando atenção para refletirmos acerca da produção de sentido que essa experiência provoca. A autora ainda afirma que essa mudança no setting analítico não se restringiu ao tradicional atendimento em consultório, pois foi necessário que os praticantes de Psicanálise se adequassem aos novos enquadres de trabalho nesse período.

A autora exemplifica então que, no âmbito da saúde pública, houve o surgimento de novos arranjos nos serviços, destacando-se experiências exitosas em atendimentos individuais e em grupo na modalidade virtual, atendimento de profissionais da equipe, de usuários internados ou de seus familiares, quando solicitado, e a possibilidade de visitas virtuais facilitadas por psicanalistas em um hospital (ROCHA, 2020).

Ainda sobre o uso das Tecnologias da Informação e Comunicação (TICs) na clínica psicanalítica, Capoulade e Pereira (2020) salientam que o seu uso já vem sendo discutido há muito tempo e que essa questão divide opiniões entre os psicanalistas, sendo possível encontrar tanto aqueles que apostam em tratamentos mediados por recursos virtuais, quanto daqueles se recusam a utilizá-los, optando apenas presencialmente, tal como é feito na clínica clássica.

Considerando o atual momento de pandemia, concordamos com Melo (2020), que faz a proposição de que a Psicanálise precisa prosseguir, e que pode fazer uso dos recursos virtuais, tendo em vista que este é o único recurso possível para atender neste momento, sem colocar em risco a proporia vida e a do outro, uma vez que o isolamento social tem sido uma das principais medidas de mitigação do contágio pelo novo coronavírus.

Todavia, embora as mídias digitais sejam uma modalidade possível atualmente, Costa (2020) argumenta sobre a necessidade de reflexão antes de aderir a esta modalidade de atendimento, apontando a presença dos estranhamentos que os atendimentos on-line 
trazem consigo, exemplificando por meio das dificuldades inerentes à escuta à distância, como também do cuidado que os psicanalistas precisam ter para que as análises não acabem se tornando psicoterapias, tendo em vista que a Psicanálise não é uma abordagem da Psicologia e muito menos uma simples abordagem psicoterápica.

Capoulade e Pereira (2020) chamam atenção para o fato de que as atuais formas de fazer Psicanálise de forma virtual, abriram caminho para que pessoas menos favorecidas do ponto de vista socioeconômico pudessem ter acesso aos psicanalistas. No entanto, alertam os perigos dessa abertura, para que os analistas não caiam no que Freud já havia alertado em sua época, que é a "Psicanálise selvagem”, que têm sido cada vez mais comum, onde pessoas se utilizam do semblante de psicanalistas para praticar o charlatanismo e ludibriar as pessoas leigas, o que nos convoca a refletir mais sobre isso.

A pandemia também intensificou as já frequentes crises de ansiedade, que são compreendidas pela Psicanálise como angústia, que segundo Lacan (1962-1963/2005) é o afeto que não engana, pois ela revela algo do desejo do sujeito. A angústia surge quando se institui a falta, pois: “[...] a falta, se esta de repente não faltar, é nesse momento que começará a angústia [...]” (LACAN, 1962-1963/2005, p. 52). Neste mesmo seminário, um pouco mais adiante, afirma que: “[...] a verdadeira substância da angústia, é aquilo que não engana, o que está fora de dúvida” (LACAN, 1962-1963/2005, p. 88).

Soler (2000-2001/2012) ressalta que a angústia não se constitui como algo estático na clínica psicanalítica, tendo em vista passar por mudanças com o passar do tempo. Isso nos ajuda a pensar então que a angústia que foi desencadeada na atual pandemia tem características próprias do nosso tempo. A autora também argumenta que a Psicanálise vai na contramão do furor sanandi disseminado pelo discurso da ciência e pelo discurso do capitalista, que tentam extirpá-la dos sujeitos, como se fosse possível excluí-la da subjetividade.

$\mathrm{Na}$ opinião da autora, antes de qualquer coisa, ao se constituir como o afeto que não engana, tal como acusou Lacan, a angústia também aponta para algo para uma radicalidade subversiva e insubmissa, funcionando como uma potência do ato criador e que ela é impossível de ser excluída da subjetividade porque é inerente à dor da existência (SOLER, 2000-2001/2012). Nesse sentido, Fingermann (2012) agrega que:

Mas, como sabemos por experiência, o que está recalcado retorna no real, ou o que sai pela porta da frente volta pela porta dos fundos. Se a angústia banida do século XXI sai do discurso comum, a ansiedade, o estresse, o nervosismo, o distúrbio de atenção, a falta de ar, o pânico 
(enaltecido como "síndrome do pânico"), entram de vento em popa tanto no senso comum quanto no discurso da ciência (FINGERMANN, 2012, p. 14).

Outra questão que a pandemia trouxe consigo foi a interrupção do processo de luto de pessoas queridas que se foram acometidas pela COVID-19, na medida em que, em decorrência de medidas sanitárias de mitigação do novo coronavírus, os mortos não puderam ser velados, não sendo possível vivenciar todo o ritual de luto do objeto perdido, e isso tem consequências perigosas para o psiquismo. De acordo com Freud (1917/2010) em seu texto intitulado "Luto e melancolia", quando perdemos um objeto precisamos fazer algo para elaborar essa perda, conceituando o luto como: “[...] a reação à de um ente querido, a perda de alguma abstração que ocupou lugar de um ente querido, como o país, a liberdade ou o ideal de alguém" (FREUD, 1917/2010, p. 46).

Freud (1916/2018) também vai discutir sobre o luto em seu texto intitulado "Transitoriedade". Nele, Freud argumenta sobre a necessidade de que precisamos compreender que as coisas são e precisam ser transitórias. Além disso, também coloca que, para que possamos abrir mão de um objeto perdido e passarmos para algo novo necessitaremos fazer o luto desta primeira coisa. Isso implica em abdicar daquilo que durante um período de nossa vida foi importante e que, consequentemente, investimos afeto sobre ele. Já Lacan (1962-1963/2005), em seu "Seminário livro 10: A Angústia", coloca que:

[...] Experimentamos o luto e sentimos seus efeitos de desvalorização na medida em que o objeto cujo luto vivenciamos era, sem que o soubéssemos, aquele que se fizera ou de quem nós fizéramos o suporte de nossa castração. Quando esta nos é devolvida, vemo-nos pelo que somos, uma vez que seríamos essencialmente devolvidos a essa posição de castração (LACAN, 1962-1963/2005, p. 125).

No que se refere ao luto em tempos de pandemia, Homem (2020) parte do pressuposto de que a pandemia nos obrigou a viver uma outra relação com a morte, tendo em vista a impossibilidade de realizar de forma convencional os rituais fúnebres diante dos avanços que o novo coronavírus teve a nível mundial, potencializando o risco de morte em decorrência da contaminação pelo corpo hospedeiro do vírus. Corroborando com a autora anterior, Kovalski (2020) acrescenta que não é possível saber como cada sujeito vai se ajeitar diante desse cenário, no entanto, acusa que essa experiência trará prejuízos à vivência do luto, não só a curto e médio, mas também a longo prazo. 
Já Brunetto (2020) assumindo uma perspectiva sociopolítica do sofrimento psíquico, sustenta que a pandemia convoca os praticantes de Psicanálise a assumirem o compromisso de, por um lado, refletirem sobre o Real de sobreviver sob ameaça de um vírus mortal e do outro de resistir ao jugo do atual governo brasileiro, o qual levanta a bandeira de um lema sanitarista-darwinista, eugenista e racista. Os psicanalistas, sabendo que sua práxis não é neutra, buscam promover fissuras nesse saber universal e consistente que é disseminado pelo bolsonarismo e sustentam, a partir da ética do bem-dizer, uma escuta subversiva e transformativa, tal como propõem Dunker e Thebas (2019).

Além disso, tal como já havia destacado Lacan, o ideal de uma análise não é o domínio completo de si ou a ausência de paixão, mas sim de: (1953-1954/2009): “[...] tornar o sujeito capaz de sustentar o diálogo analítico, de não falar nem muito, nem muito tarde. É a isso que visa uma análise didática” (LACAN, 1953-1954/2009, p. 12). Posteriormente, em seu "Seminário, livro 17: O Avesso da Psicanálise" Lacan (19691970/1992) institui então o que ele chamou de discurso do analista. Em suas palavras:

[...] Se caracterizamos um discurso centrando-nos no que é predominante, existe o discurso do analista, e este não se confunde com o discurso psicanalisante, com o discurso proferido efetivamente na experiência analítica. O que o analista institui como como experiência analítica pode-se dizer simplesmente - é a histericização do discurso. Em outras palavras, é a introdução estrutural, mediante condições artificiais, do discurso da histérica [...] (LACAN, 1969-1970/1992, p. $33)$.

Isso significa que a Psicanálise, por meio da instituição do discurso do analista e a partir da proposição de uma ética da responsabilidade: “[...] continua se empenhando em levar o sujeito a reconhecer seu próprio saber inconsciente acerca do que o atinge" (FENDRIK; JERUSALINSKI, 2011, p. 6). Forbes (2012) corrobora dizendo que o analista é aquele que irá levar o ser falante a responsabilizar-se pelo seu modo singular de gozar de seu corpo e de sua vida, responsabilidade pelo que também lhe é inconsciente.

Nesse sentido, em um cenário no qual o Real de um vírus mortal, que resultou na intensificação do mal-estar que já existia na sociedade, tal como Freud (1930/2010) já havia destacado, reafirmamos o argumento de que os praticantes de Psicanálise não devem recuar diante do atual cenário de pandemia, devendo cada profissional, respeitando as especificidades de sua atuação e estilo de analista, sustentar o discurso psicanalítico por meio de sua escuta, atentando-se para às singularidades do sujeito do inconsciente, acolhendo suas dores e incertezas que atravessam esse momento (DROGUETT, 2020). 
Tal como já havia sido proposto por Freud, Lacan (1953-1954/2009) ratifica que a Psicanálise está sempre atenta à singularidade do caso a caso, dizendo que:

Tomá-lo na sua singularidade, o que quer dizer isso? Quer dizer essencialmente que, para ele, a essência, o fundamento, a dimensão própria da análise, é a reintegração, pelo sujeito, da sua história, até os seus últimos limites sensíveis, isto é, até uma dimensão que ultrapassa de muito os limites individuais. Fundá-lo, deduzi-lo, demonstrá-lo a partir de mil pontos textuais em Freud, é o que fizemos juntos ao longo desses últimos anos (LACAN, 1953-1954/2009, p. 22).

Diante do que foi exposto ao logo deste tópico, problematizamos ainda o fato de a pandemia da COVID-19 ter impactado na saúde mental de todos, inclusive dos próprios analistas, devido às diversas imposições e restrições que a mesma trouxe consigo mudanças nas formas como o trabalho é operacionalizado, transformando as relações, que passam a acontecer de forma on-line o que, na opinião de Homem (2020), fortaleceu ainda mais o processo de naturalização da mediação das máquinas no cotidiano dos sujeitos.

A autora prossegue afirmando que a lógica on-line é uma realidade que veio para ficar e nós aprendemos a nos relacionar, trabalhar, comprar, festejar, consultar, medicar, fazer sexo, enfim, aprendemos a existir por meio das mídias digitais (HOMEM, 2020).

Logo, mesmo que a lógica que permeia esse uso da tecnologia seja a ds discuros universitário e capitalista (LACAN, 1969-1970/1992), os psicanalistas têm a tarefa de dar continuidade às análises, fazendo o discurso psicanalítico prossiga, a partir do que é possível, se adequando ao uso das mídias digitais, todavia tomando o cuidado de não se render aos preceitos mercadológicos capitalistas (GÓES, 2008).

\section{CONSIDERAÇÕES FINAIS}

[...] o fato de que o sujeito revive, rememora, no sentido intuitivo da palavra, os eventos formadores da sua existência, não é, em si mesmo, tão importante. O que importa é o que ele disso reconstrói.

LACAN, 1953-1954/2009, p. 23. 
Iniciamos estar considerações com esta citação de Lacan que, para nós é válida para pensamos a atual pandemia da COVID-19, tendo em vista que, como praticantes de Psicanálise, apostamos no poder das palavras e na potência da escuta psicanalítica como dispositivos que possibilitam aos sujeitos a rememoração de suas vivências e a elaboração de novas narrativas, a partir da ressignificação desses eventos formadores de sua existência, uma vez que, para a Psicanálise: “[...] O que importa é o que ele disso reconstrói” (LACAN, 1953-1954/2009, p. 23).

Sabemos que o trabalho analítico se tornou ainda mais difícil diante do atual cenário pandêmico, que nos impôs uma nova realidade: a da vida on-line, obrigando os sujeitos a reinventar seus modos de viver, inclusive os próprios psicanalistas, que precisaram repensar a práxis psicanalítica clássica e sustentar uma atuação por meio da realidade virtual, principalmente no início da pandemia, sendo esta a única opção segura diante da crescente a disseminação do novo coronavírus e proteger a própria vida.

Nesse sentido, ressaltamos aqui alguns aspectos que consideramos favoráveis e desfavoráveis que essa prática psicanalítica on-line evoca. Como desfavorável destacamos o fato de o trabalho remoto exigir muita preparação e habilidade por parte dos praticantes de Psicanálise para poder fazer uso das mídias digitais, exige investimento de tempo e de dinheiro para poder sustentar esta modalidade de atendimento e acreditamos que nem todos os profissionais, diante deste cenário de crise econômica e sanitária, teve condições financeiras para se adequar a essa nova realidade.

Outra problemática é a de assegurar o sigilo e o ambiente necessários para às sessões, tendo em vista que o setting, principalmente no início da pandemia, passou a casa dos analisantes e isso pode implicar no fato de que nem todos puderam dispor de um ambiente que pudesse assegurar esse sigilo. Isso também inclui a familiarização tanto dos praticantes de Psicanálise quanto dos analisantes com o uso das mídias digitais, além de dispor de uma boa conexão com a internet que possibilitasse o atendimento do início ao fim, como também de atentar-se à duração das sessões, tendo em vista as particularidades dessa modalidade.

Por outro lado, como fatores favoráveis, ressaltamos que, do ponto de vista epidemiológico, os atendimentos on-line foram um modo de mitigar a disseminação do novo coronavírus, por não necessitar de um contato presencial, além de ser considerado mais econômico para o profissional, tendo em vista que não precisa de sublocação de sala e nem que seja obrigatório o deslocamento para sua realização, possibilita tanto ao 
praticante de Psicanálise, quanto a quem procurasse seus serviços um maior escopo de possibilidades, a partir da interação com pessoas de diferentes cidades, regiões, estados e até países.

Logo, diante do mal-estar contemporâneo em tempos de pandemia, problematizamos o que pode a Psicanálise de Orientação Lacaniana, ancorada em uma dimensão sócio-política do sofrimento psíquico, indo na contramão do psicologismo, da psiquiatrização e da medicalização estigmatizantes. Assim, através de sua escuta, o praticante de Psicanálise atua como um agente de transformação social, contribuindo para a subversão da lógica político-social vigente, apostando no sujeito da linguagem, ressaltando a sua singularidade e na diferença de cada invenção, tal como destaca Soler (2001-2002/2019) a Psicanálise permanece resistindo aos discursos das neurociências, psicofarmacologia e psicoterapias e entre estas, produzindo furos na consistência destes discursos que se propõem como universais.

\section{REFERÊNCIAS}

BASTOS, R. L. Psicanálise e pesquisas: Ciência? Arte? Contraciência?. $2^{\mathrm{a}}$ ed. Rio de Janeiro: E-papers, 2009.

BRUNETTO, A. Psicanálise on-line: possibilidades e limites. In: FÓRUM DO CAMPO LACANIANO. (Org.). Psicanálise e pandemia. São Paulo: Aller, 2020, p. 95-100.

CAPOULADE, F.; PEREIRA, M. E. C. Desafios colocados para a clínica psicanalítica (e seu futuro) no contexto da pandemia de COVID-19: reflexões a partir de uma experiência clínica. Revista Latinoamericana de Psicopatologia Fundamental. São Paulo, v. 23, n. 12. Ago. 2020, p. 534-548. Disponível em: <https://www.scielo.br/j/rlpf/a/WbtCvSVsHbMJPWxMjyPbTcG/formathtml\&langpt>. Acesso em 28 Nov. 2021.

COSTA, M.; SIQUEIRA, T. Prefácio. In: FÓRUM DO CAMPO LACANIANO/MS. (Org.). Psicanálise e pandemia. São Paulo: Aller, 2020, p. 5-12.

COSTA, M. A pandemia que nos quebra, como cristais. In: FÓRUM DO CAMPO LACANIANO. (Org.). Psicanálise e pandemia. São Paulo: Aller, 2020, p.139-146.

DROGUETT, J. Sobre o mal-estar na pandemia: o papel da psicanálise em tempos de coronavírus. Revista Leitura Flutuante. São Paulo, v. 12, n. 1, Set. 2020, p. 75-93. Disponível em: <https://revistas.pucsp.br/index.php/leituraflutuante/article/view/5041>. Acesso em 16 Out. 2021.

DUNKER, C. I. L.; THEBAS, C. O Palhaço e o psicanalista: como escutar os outros pode transformar vidas. São Paulo: Planeta, 2019. 
FENDRIK, S.; JERUSALINSKI, A. Introdução. In: JERUSALINSKY, A.; FENDRIK, M. (Orgs.). O Livro negro da psicopatologia contemporânea. São Paulo: Via Lettera, 2011, p. 05-12.

FINGERMANN, D. Apresentação: Consideração da angústia. In: SOLER, C.

Declinações da angústia (2000-2001). São Paulo: Escuta, 2012, p. 7-14.

FORBES, J. Inconsciente e responsabilidade: psicanálise do século XXI. Barueri/SP: Manole, 2012.

FORTES, I.; MACEDO, M. K. Quem é o psicanalista pesquisador? Questões cruciais sobre o método psicanalítico de pesquisa. In: FULGÊNCIO, L. et al. (Orgs.).

Modalidades de pesquisa em psicanálise: métodos e objetivos. São Paulo: Zagodoni, 2018, p. 106-122.

FREUD, S. O mal-estar na civilização, novas conferências introdutórias à psicanálise e outros textos (1930-1936). São Paulo: Companhia das Letras, 2010. Obras Completas de Sigmund Freud, v. 18.

FREUD, S. Introdução ao narcisismo, ensaios de metapsicologia e outros textos (1914-1916). São Paulo: Companhia das Letras, 2010. Obras Completas de Sigmund Freud, v. 12.

FREUD, S. Transitoriedade (1917). In: FREUD, S. Arte, literatura e os artistas. Belo Horizonte: Autêntica Editora, 2018, p. 221-226. Obras Incompletas de Sigmund Freud.

GÓES, C. Psicanálise e capitalismo. Rio de Janeiro: Garamond Universitária, 2008.

HARARI, A. Fundamentos da prática lacaniana: risco e corpo. Belo HorizontelMG: Relicário, 2018.

HOMEM, M. L. Lupa da alma: Quarentena- revelação. São Paulo: Todavia, 2020.

KAMLER, B.; THOMSON, P. Trabalhando com literaturas. In: SOMEKH, B; LEWIN, C. (Orgs.). Teoria e método de pesquisa social. Petrópolis/RJ: Vozes, 2015, p. 45-55.

KOVALSKI, M. Morte e luto na pandemia. In: FÓRUM DO CAMPO LACANIANO. (Org.). Psicanálise e pandemia. São Paulo: Aller, 2020, p.193-198.

LACAN, J. O lugar da psicanálise na medicina (1966). Opção Lacaniana On-line. São Paulo, n. 32, v. 6, n. 7, Dez. 2001, p. 8-14. Disponível em:

<https://pt.scribd.com/document/359168/Lacan-o-Lugar-Da-Psicanalise-Na-Medicina>. Acesso em 26 Nov. 2021.

LACAN, J. O Seminário, livro 17: o avesso da psicanálise (1969-1970). Rio de Janeiro: Zahar, 1992.

LACAN, J. O Triunfo da religião, precedido de discurso aos católicos (1974). Rio de Janeiro: Zahar, 2005. Série Paradoxos de Lacan. 
LACAN, J. Função e campo da fala e da linguagem. In: LACAN, J. Escritos. Rio de Janeiro: Zahar, 1998, p. 322.

LACAN, J. O Seminário, livro 10: A Angústia. 1962-1963. Rio de Janeiro: Zahar, 2005.

LACAN, J. O Seminário, livro 1: Os escritos técnicos de Freud (1953-1954). $2^{\text {a }}$ ed. Rio de Janeiro: Zahar, 2009.

PREUSS, F. C. et al. E como ficam nossos desejos? Um olhar psicanalítico sobre a pandemia do COVID-19. Anuário Pesquisa e Extensão UNOESC. São Miguel do Oeste, v. 5, p. e24162-e24162, 2020. Disponível em:

<https://portalperiodicos.unoesc.edu.br/apeusmo/article/view/24162/14241>. Acesso em 28 Nov. 2021.

QUINET, A. Análise on-line em tempos de pandemia. In: FÓRUM DO CAMPO LACANIANO - MS (Org.). Psicanálise e pandemia. São Paulo: Aller, 2020, p. 13-30.

MELO, R. Análise on-line no tempo da pandemia. In: FÓRUM DO CAMPO LACANIANO. (Org.). Psicanálise e pandemia. São Paulo: Aller, 2020, p. 81-87.

RIBEIRO, M. A. T.; MARTINS, M. H. M.; LIMA, J. M. A pesquisa em bases de dados: como fazer? In: LANG, C. E. et al. Metodologias: pesquisas em saúde, clínica e práticas psicológicas. Maceió: EDUFAL, 2015, p. 61-84.

ROCHA, A. P. B. Psicanálise em tempos de pandemia: o que pode o psicanalista?. Revista Brasileira de Psicanálise. Rio de Janeiro, v. 54, n. 2, Set. 2020, p. 59-72. Disponível em: <http://pepsic.bvsalud.org/pdf/rbp/v54n2/v54n2a05.pdf>. Acesso em 16 Out. 2021.

ROSA, M. D. A Clínica psicanalítica em face da dimensão sociopolítica do sofrimento. $2^{\text {a }}$ ed. São Paulo: Escuta/FAPESP, 2018.

ROUDINESCO, E.; PLON, M. Dicionário de psicanálise. Rio de Janeiro: Zahar, 1998. SAFATLE, V. Introdução a Jacques Lacan. $4^{\mathrm{a}}$ ed. Belo Horizonte: Autêntica, 2018. SOLER, C. Declinações da angústia (2000-2001). São Paulo: Escuta, 2012.

SOLER, C. O Em-corpo do sujeito: seminário 2001-2002. Salvador: Ágalma, 2019. 